\title{
Trustless Technology within Trust-Based Systems; A Comparative Study of the Big Four's Approach to Blockchain Adoption and its Future Prospects
}

\author{
Amjad Pirotti (Corresponding author) \\ University of Malaya, Kuala Lumpur, Malaysia \\ E-mail: amjadpirotti@gmail.com \\ Amir Roknifard \\ 4508 Ave SE, Calgary, AB, Canada \\ E-mail: roknifard@gmail.com
}

Received: May 27, 2020 Accepted: June 13, 2020 Published: June 26, 2020

doi:10.5296/bms.v11i1.17095 URL: https://doi.org/10.5296/bms.v11i1.17095

\begin{abstract}
Technological developments and industrial adaptations are leading to a fundamental change in how industries and strategy function in the world today. Disruptive technologies are forcing us to reconsider the way we make decisions, and the models that were previously in place for delivering products and services. Blockchain in particular has demonstrated its ability to completely upend industry as we know it. Its main strengths lie in the fact that it is decentralized, unchangeable, anonymous and auditable. In this paper, we present a comparative study on the Big Four accounting firms' approach to Blockchain development and adoption. We first give an overview of the blockchain technology and key characteristics of the blockchain and its applications. Furthermore, we discuss some existing approaches for blockchain development and application in the Big Four accounting firms and highlight the opportunities and future prospects of blockchain technology that can be utilized by the four professional services conglomerates.
\end{abstract}

Keywords: blockchain, disruptive technologies, digital transformation, smart contract, big four 


\section{Introduction}

The business models that so many long-standing organizations rely on are being undermined, or completely replaced, through the development of new technologies. This shouldn't come as a surprise; the market for developments such as blockchain is more accessible than ever, and developing all the time. The organizations that find themselves able to innovate through digital technology are forging ahead, creating new paradigms and shifting the way we approach business (Lucas et al., 2013). Programmable contracts, or smart contracts, which can run without the direct support or intervention of a human being, are able to computerize or replace many traditional institutions, such as banks and insurance (Swan, 2015; Tapscott and Tapscott, 2016).

Condos et al. (2016) define a blockchain as an electronic ledger, or register, holding records, events and transactions. The blockchain is managed by a shared computer network. Trade records were not historically available to the public, making the open availability of such information to any interested party a key development in blockchain's technology. Any prior transaction is viewable. This renders central supervision unnecessary as, in blockchain, the shared network is able to check transactions at any time. This is thought to be one of the leading innovations of blockchain (Harvard Business Review, 2017). Removing the need for that central entity is representative of a significant move towards more direct transactions, away from the use of intermediaries (Tapscott and Tapscott, 2016).

The best-known, and undoubtably most publicized, use for blockchain is Bitcoin, however blockchain has a wide range of potential applications aside from cryptocurrency. Blockchain creates an opportunity for making payments without the involvement of a bank or other financial intermediary, potentially making it useful in a number of financial services including digital assets and online payments (Peters et al., 2015; Foroglou and Tsilidou, 2015). It's also being investigated for a possible role in future online interaction systems. For example, a blockchain model of cryptography for smart contracts (Kosba et al., 2016), use in public services (Akins et al., 2013), in combination with internet of things (IoT) to enable new methods of transactions (Zhang and Wen, 2015), in development of reputation systems (Sharples and Domingue, 2016) and to improve effectiveness of security services (Noyes, 2016a).

The peer-to-peer, decentralized nature of blockchain is one of its most popular features and, although much of the work on blockchain is overshadowed by Bitcoin, there a huge number of possible applications for blockchain beyond Bitcoin (Zheng et al., 2018). It is anticipated that blockchain will be the cause of major changes in the processes for accounting and auditing. Because blockchain not only records transactions, but also creates a protected and persistent record of those transactions, it is completely auditable through coding. With this in mind, it seems clear that blockchain will dramatically alter bookkeeping in the corporate sphere.

'Big Four' accounting firms, PricewaterhouseCoopers (PwC), Deloitte, Ernst \& Young (EY) 


\section{Macrothink

and KPMG, have all worked on long-term plans to ensure that they can maintain their significance as cryptocurrency and blockchain gain popularity. These four professional services firms have a combined workforce of more than a million people, and each has different plans in development in response to the perceived future of the blockchain industry. They have invested significant effort into both understanding and assimilating the technology as it develops, while also recognizing the current gaps in regulations around blockchain and its implications. In this paper, an overview of blockchain technology application in accounting industry is discussed. Furthermore, a comparative approach has been taken to discuss the Big Four accounting firms and their approach to blockchain development and adoption.

\section{Accounting Industry and Blockchain Technology}

It's easy to assume that the development of blockchain will render accounting as a profession completely irrelevant, between blockchain's capacity to self-audit, as well as its persistency. However, looking past that, there are some potentially significant benefits this technology can bring to the whole industry. That's not to say there are no valid concerns at this stage; both the lack of current regulation in the area and the threat of future obsolescence of current technologies have been raised as issues by early blockchain adopters. As its popularity begins to grow, blockchain will highlight more unnecessary and unsecure accounting processes. Naturally, the next question to be raised is around cybersecurity and scalability, and the growth potential of blockchain technology as a replacement to these established practices. The future relationship between accounting and blockchain is an uncertain one, as becomes clear in any look at the broader questions around industry growth or decline (Karajovic et al., 2019).

Figure 1 provides a visual comparison of a centralized and a decentralized system of accounting. A centralized system involves a significant amount of document exchange to facilitate a transaction, including purchase orders, invoices and receipts. In a decentralized system, an electronic transfer of funds simply requires the initiator's bank to send the funds to the recipient, and the recipient to confirm receipt of the payment. In this system, if the transaction takes place on the blockchain network, data miners can authenticate the payment having confirmed that all established conditions are met (Kuhn, 2018). 
Centralized System

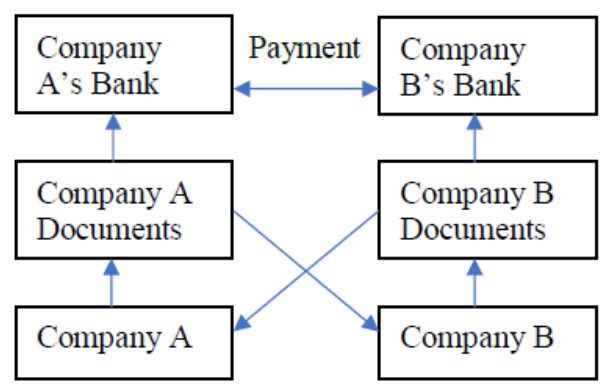

Decentralized System

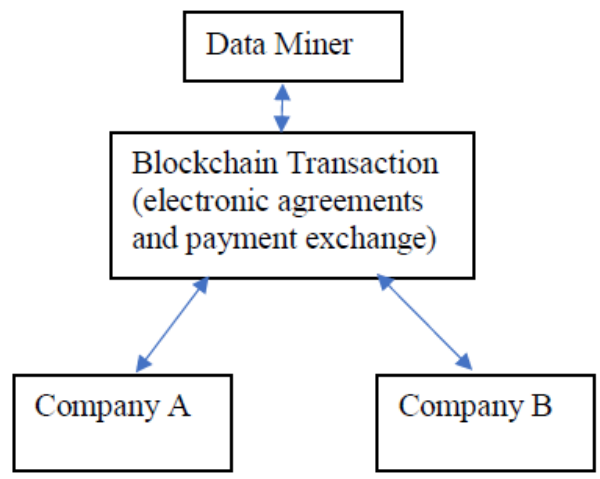

Figure 1. Centralized System vs. Decentralized System (Kuhn, 2018)

Blockchain accounting systems are decentralized, with independent third-party verification of transactions, in stark contrast to the more traditional centralized databases. Blockchain's structure, with a decentralized database, hinges on the use of third-party validation that a transaction has been confirmed by both parties, and that the goods or services have been exchanged before payment is actioned. Transactions can be verified by a third party anywhere in the world, providing they have an internet connection (Adriano and Monroe, 2016).

Joseph M. Woodside et al. (2017) considered four environmental factors (political, economic, social and technical) and used a triangulation strategy, investigating the point of acceptance of blockchain technology. Table 1 shows each of those four environmental factors, describing the drivers and drawbacks of each.

Table 1. Blockchain Technology Environment Analysis (Woodside et al., 2017)

\begin{tabular}{|c|l|l|}
\hline \multicolumn{1}{|c|}{ Factor } & \multicolumn{1}{|c|}{ Drivers } & \multicolumn{1}{c|}{ Drawbacks } \\
\hline Political & $\begin{array}{l}\text { Transparency: public blockchains are } \\
\text { viewable by all participants and } \\
\text { cannot be altered, allowing trust of } \\
\text { transactions without a required } \\
\text { regulatory party. }\end{array}$ & $\begin{array}{l}\text { Regulatory Status: currencies have } \\
\text { traditionally been regulated by } \\
\text { national governments. International } \\
\text { adoption rates vary, a recent SEC } \\
\text { disapproval of a planned Bitcoin ETF } \\
\text { cited unregulated markets. }\end{array}$ \\
\hline Economic & $\begin{array}{l}\text { Costs: blockchain has the ability to } \\
\text { automate a number of existing } \\
\text { functions, and lowers transaction } \\
\text { costs and improves completion time } \\
\text { by removing the need for third-party }\end{array}$ & $\begin{array}{l}\text { Volatility: currency fluctuations have } \\
\text { impacted value of market and } \\
\text { susceptible to market shocks. }\end{array}$ \\
\hline
\end{tabular}




\begin{tabular}{|c|c|c|}
\hline & intermediary transaction fees. & \\
\hline Social & $\begin{array}{l}\text { User Control: ability to monitor } \\
\text { transactions in a single location. }\end{array}$ & $\begin{array}{l}\text { Privacy and Security: publicized } \\
\text { concerns of transaction privacy and } \\
\text { security incidents limit user adoption. }\end{array}$ \\
\hline Technical & $\begin{array}{l}\text { Quality: decentralized reliability, } \\
\text { durability and security, no } \\
\text { centralized server or single point of } \\
\text { failure, greater protection against } \\
\text { fraudulent transactions. }\end{array}$ & $\begin{array}{l}\text { Innovation: resolution of speed, } \\
\text { processing time, security and privacy } \\
\text { concerns, and integration within } \\
\text { existing systems and networks. }\end{array}$ \\
\hline
\end{tabular}

Blockchain shows potential to disrupt and evolve a number of business areas. The accounting industry in particular looks likely to be impacted enormously as blockchain becomes more widely adopted, with a number of currently manual processes held as standards heading for automation with blockchain's introduction. As one example, there is a double entry system in place in the accounting industry presently, which is carefully audited. The system is useful in authentication and ensuring accuracy, it's also both labor- and time-intensive as a practice. With the methods currently in place, automation would be completely unworkable. However, using blockchain, companies could document all transactions directly into a joint register to create a persistent chain of records. The unchangeable nature of blockchain means that, once each transaction was verified and recorded, it would be almost impossible to alter or falsify any of the information (Deloitte, 2016).

\section{The Big Four Accounting Firms and Blockchain Adoption}

Within the last decade there has been a significant increase in research into emerging technologies and their possible impact across industries, from supply chains and resources to training and employment. At this stage, there is still intense debate around which industries will see the greatest benefits and which will suffer as a result of disruptive technologies such as blockchain. The rate of change is significant, and the current technology revolution looks set to have an impact even greater, potentially, than that of the industrial revolution (Evans, 2017). A 2016 survey conducted by KPMG UK found that technology companies, the previous leaders of technology disruption, are in the process of finding themselves overtaken by smaller, more agile start-ups. One third of the boards of these larger technology companies said that they were not prepared for the disruption (KPMG, 2016).

An investigation of recent blockchain developments by the Big Four accounting firms serves to emphasize the disruptive nature of this new development. $\mathrm{PwC}$ is both testing a range of blockchain technologies, and providing advice to clients on their applications. PwC Australia is also working together with a group of blockchain start-ups (Netki, Bloq and Libra) to develop a 'multi-asset' blockchain platform. This platform, called Vulcan, exists to develop exchangeable assets for trading with cryptocurrency (Miles, 2017). Before this project, PwC 
also worked with Blockstream, a provider of Bitcoin technologies, to offer blockchain services to other firms worldwide (Rizzo, 2016). In addition to these, $\mathrm{PwC}$ is currently collaborating with another Blockchain as a Service (BaaS) company, BitSE, to encourage greater adoption of blockchain in the Asia-Pacific market (Ji, 2016). What can be seen through all of these projects is PwC taking advantage of its global resources and taking on a truly global mindset. PwC appears to be closely tracking international responsiveness to this new technology, as well as investigating a range of possible uses across different markets (Karajovic et al., 2019).

Deloitte has also taken a proactive approach to internal blockchain development. The firm began working on its own blockchain platform, like Vulcan, in 2014. Rubix, its most widely-known platform, was developed to make the auditing of blockchain transactions quicker and simpler. The focus of Vulcan was on improving banking by recombining bitcoin and other popular cryptocurrencies with its blockchain. Deloitte, on the other hand, has focused its efforts on applying blockchain to the effective management of supply chains. Deloitte's blockchain development efforts involve over 800 employees, across 20 countries (Faile, 2017). Deloitte opened its first blockchain facility in Ireland in May 2016, and by the following January this had been joined by a second lab, this time in New York, with a focus on the development of so-called 'ready-to-integrate' blockchains (Faile, 2017). With these efforts, Deloitte has demonstrated an understanding of the advantages of early adoption, and an undertaking of large-scale digital adaptation to enhance its client service offerings.

EY has taken a different approach on the other hand, working alongside consulting firm Accenture to experiment with editable blockchains. Accenture has suggested that exploration of permissioned blockchains which are able to be modified could be useful when having to respond to unforeseen real-world events (Redman, 2016). Detractors combat this by arguing it undermines blockchain's key strengths, namely the fact that it is decentralized and unchangeable. In February 2017, EY revealed plans to put out an identity management blockchain for one of its Australian clients, including Know-Your-Customer (KYC) precautions (Keane, 2017). EY appears to be taking a particularly broad and varied angle on its approach to blockchain development.

Turning now to KPMG, this firm has worked alongside Microsoft to offer Digital Ledger Services, advising clients on the advantages of blockchain for increasing the speed and security of transactions, reduce costs and streamline processes (KPMG, 2017). These services will provide what they refer to as 'lifecycle support', assisting clients in maintaining their blockchain infrastructure from the point of adoption (KPMG, 2017). They also released Blockchain Nodes in February 2017, 'Innovation workspaces' designed to generate and mimic blockchain use cases. The sites for the first of these facilities were Frankfurt and Singapore, and there is another location anticipated soon in New York. Microsoft's Azure cloud platform supports the workspaces, which the company uses primarily to offer BaaS (Miller et al., 2017), much like BitSE. KPMG's decision to partner with Microsoft, a leading technology company, emphasizes the importance placed on this early blockchain research. 


\subsection{Opportunities and Future Prospects}

When looking at the responses of the Big Four firms to blockchain's emergence, a certain pattern emerges. All of the organizations openly acknowledge the enormous potential disruption blockchain represents, and all of them are committed to investigating the technology's wide-ranging uses. They are also in the process of executing a range of blockchain technologies - private, public and permissioned - to respond to the needs of their customers (Karajovic et al., 2019). The bulk of the work so far has focused on the use of blockchain to enhance client services. However, blockchain offers enormous utility in the area of internal accounting management as well. The Pareto principle suggests that $80 \%$ of organizational issues are solvable by streamlining processes, and $20 \%$ of the solutions for this come from disruptive technologies (Boomer, 2016). It therefore follows that blockchain holds the answers for improving or removing any number of unwieldy processes and methods, specifically in tax and assurance (Boomer, 2016). The most obvious shift is one mentioned earlier in this article, moving away from double-entry accounting and moving instead to a triple-entry accounting system. The bookkeeping method in place at present results in an agency issue for accountants, raising a conflict of interest between maximizing management's objectives and providing reliable information to the public for decision-making (Andersen, 2016).

Blockchain's natural advantage here is that it allows for real-time tracking of entries, reducing the room for biased judgement and ensuring completely accurate representation of information. The double-entry approach which is currently standard requires one party to register a debit and a credit in the company's records. Blockchain, on the other hand, has the seller document a debit and the purchaser document a credit (Watson, 2017). The real-time element is of particular importance for parties such as assurance providers, advisors and stakeholders; the ability to track transactions as they happen guarantees both honesty and full transparency. Not only is this helpful when drawing up financial reports, the real-time recording of transactions can have a beneficial impact on productivity and business analytics (Watson, 2017). The availability of accurate historical data, and the ability to track it efficiently, makes it easier to understand a company's financial position and performance. In addition, the real-time entries can make it easier to find hidden accounts or smaller details that would previously have gone unnoticed (Tapscott, 2016). The up-to-date figures can be translated into valuable information regarding any resources being wasted, unnecessary processes and sources of congestion in the current methods. Blockchain, with its real-time capabilities, provides accountants with an opportunity to spend their time and efforts on this kind of work, cutting back on the time required for verifying a company's accounting records (Karajovic et al., 2019).

Yet another way in which blockchain can increase efficiency is by use of smart contracts. A smart contract is a self-executing contract, in which the contract's terms are written into code within the blockchain. That code will execute in response to pre-determined conditions. Smart contracts do not only have applications in the legal and managerial spheres, they can 
be used to replace any automatable task. This includes a wide range of administrative and operational activities. A smart contract can automatically update an account, validate whether certain goals or metrics are being achieved, and significantly speed up the preparation of reports for both internal and external use (Wunsche, 2016). Even taxes can be automated through blockchain. The accounting processes in place presently involve calculation of revenue and subsequent tax allocation in retrospect, whereas blockchain creates the possibility of recognizing and recording each of those in real-time. Tax evasion would be essentially impossible under such a system, which would reduce the cost associated with tax compliance for a number of organizations (Karajovic et al., 2019).

\section{Conclusion}

A popular analogy for blockchain is the development and popularization of the internet in the 1990s. Many of the conversations and debates, about how to regulate the internet and the conflicts that existed between various agencies, have their analogues today in the conversations around blockchain. Today, of course, the internet is a technology that impacts almost everybody on a daily basis (Boring, 2016). Again, much like the internet, organizations who are prepared to embrace the changes blockchain looks set to bring are more likely to see success over the long-term. Some consider blockchain to be a technological innovation, but some go even further and claim that blockchain forms the technological basis for a new economy (Swan 2015). Blockchain is affecting the level of trust between parties entering into a transaction, and it provides a fuller and more transparent audit trail than sample testing. Many companies are taking steps towards blockchain as a method of tracing transactions made between those participating in the financial markets. The Big Four accounting firms are exploring a range of avenues in their preparations for blockchain, showing an awareness of the probability that blockchain will alter or eradicate the human component of transaction verification.

The Big Four companies are both recognizing and responding to the increasing interest in blockchain technology, although each one is adopting a different method. PwC is taking a direct approach, seeking to integrate blockchain technology into the existing infrastructure of firms, while Deloitte has honed in on improvements to the technical components of blockchain. In contrast, KPMG and EY seem to have dedicated the bulk of their resources to risk analysis around the application of blockchain technology, and creating tools to make the process of using blockchain more straightforward.

\section{References}

Adriano, A., \& Monroe, H. (2016). The Internet of Trust. Retrieved on March, 05, 2016.

Akins, B. W., Chapman, J. L., \& Gordon, J. M. A whole new world: Income tax considerations of the bitcoin economy (2013).

Andersen, N. (2016). Blockchain Technology: A game-changer in accounting? Deloitte. p. 2

Boomer, L. G. (2016). Blockchain: What it is, and why it matters to CPAs. Accounting Today, 
30(10), p. 26.

Boring, P. (2016). What the Internet was for your parents, the blockchain will be for you. Retrieved on August, 19, 2016.

Bradbury, D. (2015, February 09). How the Blockchain Could Stop Firms Cooking the Books. CoinDesk. Retrieved on February, 09, 2015.

Brender, N., Gauthier, M., Morin, J. H., \& Salihi, A. (2019). The potential impact of blockchain technology on audit practice. Journal of strategic innovation and sustainability, 14(2), 35-59. https://doi.org/10.33423/jsis.v14i2.1370

Condos, J., Sorrell, W. H., \& Donegan, S. L. (2016). Blockchain technology: Opportunities and risks. Vermont, January, 15.

Deloitte. (2016). Blockchain Technology A game-changer in accounting?. Retrieved on September, 21, 2016.

Faile, C. (2017). Deloitte Launches Blockchain Lab in New York, Increasing Focus on Key Technology in 'Make-or-Break' Year. Retrieved on January, 12, 2017.

Foroglou, G., \& Tsilidou, A. L. (2015). Further applications of the blockchain. In 12th student conference on managerial science and technology.

Hambiralovic, M., \& Karlsson, R. (2018). Blockchain Accounting in a Tripple-Entry System.

Harvard Business Review. (2017). Blockchain - What You Need to Know. Retrieved on June, 19, 2017.

Ji, K. (2016). PwC announces strategic alliance with BitSE to accelerate the use of blockchain in China \& HK markets. Retrieved on June, 16, 2016.

Karajovic, M., Kim, H. M., \& Laskowski, M. (2019). Thinking outside the block: Projected phases of blockchain integration in the accounting industry. Australian Accounting Review, 29(2), 319-330.

Keane, J. (2017). 'Big Four' Firm EY Begins Blockchain ID Platform Rollout. CoinDesk. Retrieved on February, 28, 2017.

Kosba, A., Miller, A., Shi, E., Wen, Z., \& Papamanthou, C. (2016). Hawk: The blockchain model of cryptography and privacy-preserving smart contracts. In 2016 IEEE symposium on security and privacy (SP) (pp. 839-858). IEEE.

KPMG LLP. (2017). KPMG and Microsoft Blockchain services. Retrieved on September, 16, 2017.

KPMG. (2016). Artificial intelligence opens the door to the creative CFO. KPMG International Research. London, UK.

KPMG. (2016). The disruptors are the disrupted. Disruptive technologies barometer: Technology sector. KPMG International Research. London, UK.

Kuhn, B. D. (2018). The Impact of Blockchain Technology on Business, Financial Auditors, and Accounting Professionals.

Llewellyn Evans, G. (2017). Disruptive technology and the board: The tip of the iceberg. 
Economics and Business Review, 3(1). https://doi.org/10.18559/ebr.2017.1.11

Lucas Jr, H., Agarwal, R., Clemons, E. K., El Sawy, O. A., \& Weber, B. (2013). Impactful research on transformational information technology: an opportunity to inform new audiences. Mis Quarterly, 371-382. https://doi.org/10.25300/MISQ/2013/37.2.03

Miles, B. (2017). Trends From CoinDesk's New 2017 State of Blockchain Out Today. Retrieved on February, 19, 2017.

Miller, K., \& Settles, P. (2017). KPMG And Microsoft Announce Blockchain Nodes. Retrieved on February, 15, 2017.

Nakamoto, S. (2008). Bitcoin: A peer-to-peer electronic cash system," http://bitcoin.org/bitcoin.pdf.

Noyes, C. (2016a). Bitav: Fast anti-malware by distributed blockchain consensus and feedforward scanning. arXiv preprint arXiv:1601.01405.

Noyes, C. (2016b). Efficient blockchain-driven multiparty computation markets at scale. Technical report.

Peters, G. W., \& Panayi, E. (2016). Understanding modern banking ledgers through blockchain technologies: Future of transaction processing and smart contracts on the internet of money. In Banking beyond banks and money (pp. 239-278). Springer, Cham. https://doi.org/10.1007/978-3-319-42448-4_13

Peters, G., Panayi, E., \& Chapelle, A. (2015). Trends in cryptocurrencies and blockchain technologies: A monetary theory and regulation perspective. Journal of Financial Perspectives, 3(3). https://doi.org/10.2139/ssrn.2646618

Puschmann, T. (2017). Fintech. Business \& Information Systems Engineering, 59 (1). https://doi.org/10.1007/s12599-017-0464-6

Redman, J. (2016). Accenture and EY Making Moves to Grow Blockchain Technology. Bitcoin.com. Retrieved on September, 06, 2016.

Riasanow, T., Burckhardt, F., Soto Setzke, D., Böhm, M. and Krcmar, H. (2018). The Generic Blockchain Ecosystem and its Strategic Implications. In: Twenty-fourth Americas Conference on Information Systems.

Rizzo, P. (2016). PwC Director: Blockchain Impact Could Create Winners and Losers. Retrieved on February, 24, 2016.

Sharples, M., \& Domingue, J. (2016). The blockchain and kudos: A distributed system for educational record, reputation and reward. In European conference on technology enhanced learning (pp. 490-496). Springer, Cham. https://doi.org/10.1007/978-3-319-45153-4_48

Swan, M. (2015). Blockchain: Blueprint for a New Economy. Sebastopol, CA: O'Reilly Media.

Tapscott, D., \& Tapscott, A. (2016, December 07). How Blockchain Will Change Organizations. MIT Sloan Management Review.

Tapscott, D., \& Tapscott, A. (2016). Blockchain revolution: how the technology behind bitcoin is changing money, business, and the world. Penguin. 


\section{Macrothink}

Business Management and Strategy

ISSN 2157-6068

2020, Vol. 11, No. 1

Watson, L., \& Mishler, C. (2017). Get Ready for Blockchain. Strategic Finance, 98(7), pp. 62-63.

Woodside, J. M., Augustine Jr, F. K., \& Giberson, W. (2017). Blockchain technology adoption status and strategies. Journal of International Technology and Information Management, 26(2), 65-93.

Wunsche, A. (2016). Technological Disruption of Capital Markets and Reporting? An Introdution to Blockchain. CPA Canada, p. 17

Zhang, Y., \& Wen, J. (2015). An IoT electric business model based on the protocol of bitcoin. In 2015 18th international conference on intelligence in next generation networks (pp. 184-191). IEEE. https://doi.org/10.1109/ICIN.2015.7073830

Zheng, Z., Xie, S., Dai, H. N., Chen, X., \& Wang, H. (2018). Blockchain challenges and opportunities: A survey. International Journal of Web and Grid Services, 14(4), 352-375. https://doi.org/10.1504/IJWGS.2018.095647

\section{Copyright}

Copyright for this article is retained by the author(s), with first publication rights granted to the journal.

This is an open-access article distributed under the terms and conditions of the Creative Commons Attribution license (http://creativecommons.org/licenses/by/4.0/). 